\title{
COMPUTER ANALYSIS OF THE GMAW AND GMAW-CW WELDING THERMAL CYCLES
}

\author{
E. A. M. Mendonça, \\ E. M. Braga, \\ A. S. A. Ferreira, \\ R. R. Maciel, \\ T. S. Cabral, \\ and J. T. B. Lopes \\ Universidade Federal do Pará \\ Departamento de Engenharia Mecânica \\ Rua Augusto Corrêa \\ 66075110, Belém, Pará, Brasil \\ edbraga@ufpa.br \\ Received: September 14, 2015 \\ Revised: October 09, 2015 \\ Accepted: November 09, 2015
}

\section{ABSTRACT}

A novel process of welding GMAW-CW (Gas Metal Arc Welding-Cold Wire) had been developed with it resemblance to the GMAW (Gas Metal Arc Welding), the GMAW-CW has an additional wire fed into de weld pool, allowing better deposition rates, while maintaining weld characteristics. However, there is a more complex situation related to the HAZ (Heat Affected Zone) and weld geometry prediction than the GMAW conventional. The welding energy is a high metallurgical important parameter because together with the geometric characteristics of the gasket and the preheat level is decisive in thermal cycles imposed to the material, and therefore in the possible microstructural transformations and behavior of the joint. The behavior of representative curves of thermal cycling reflects important aspects regarding the conditions used in welding. Usually such factors as the type of process, use or non- pre or post- heating, heat input, multipass welding, are able to establish differences in the form of a heat cycle curve. In this work, it was applied the dual ellipsoidal model of heat input, adapted to the GMAW-CW and compared to the same model over the GMAW, using existing experimental data and predicting the HAZ dimensions in function of weld and welding parameters. The results found had less than $10 \%$ error from experimental data in a more refined version of the model, whereas the difficulties to predict cold wire addition influences were not trivial.

Keywords: gmaw, gmaw-cw, fem, dual ellipsoidal, haz

\section{NOMENCLATURE}

a,b,c energy density distribution parameters, $\mathrm{m}$ CTWD contact tip to work distance, $\mathrm{mm}$ $\mathrm{CC}+$ current continuous positive

$f_{f} \quad$ ellipsoids frontal heat fractions

$f_{f} \quad$ ellipsoids rear heat fractions

$\mathrm{F}_{\mathrm{s}}$ force, $\mathrm{N}$

$K_{s} \quad$ strengthening matrix

$K_{t} \quad$ conductivity matrix

$q(x, y, z, t)$ energy density distribution, $\mathrm{W} / \mathrm{m}^{3}$

$\mathrm{Q}$ heat charge, $\mathrm{W}$

$\mathrm{Q}_{\mathrm{s}} \quad$ displacement, $\mathrm{m}$

$\mathrm{t} \quad$ welding time, $\mathrm{s}$

$\mathrm{T}$ temperature, ${ }^{\circ} \mathrm{C}$

$\mathrm{U}$ tension, $\mathrm{V}$

$\mathrm{V}_{\text {eletrode }}$ electrode velocity, $\mathrm{m} / \mathrm{min}$

$\mathrm{x}, \mathrm{y}, \mathrm{z}$ cartesian coordinates, $\mathrm{m}$

\section{INTRODUCTION}

Naval industry has steel as its base for construction and welding as main joining process. Due to the increase of the demand in marine transports, a better production is need, whereas computational methods can be used as tools for less expensive improvements. This way, welding parameters have an important row in the production improvements.

The GMAW welding process according to Scotti and Ponomarev (2008) is based in an electric arc heat source between a wire, continuously fed and the piece. The protection of the arc is made either through a protective atmosphere of inert gas, active gas or a mixture. However, in the GMAW-CW there is an additional non-energized wire that does not need any expensive extra apparatus or training to welding procedures, being versatile for automated or semiautomated welding (Sábio, 2007; Barcelar and Ferraz, 2005). This process requires only an additional feeder and a support on the torch.

This work was developed in order to evaluate the welds geometries thermal effects over the SAE 1020 base metal, through temperatures profiles during a Finite Element Analysis (FEM). The model for heat flux due welding was based in a previous work (Goldak, 1984), whereas several parameters are to be determined through experimental data in order to predict heat affected zones and melting zones.

The Finite Element Method (FEM) consists in a numerical method of several physics phenomenon in continuous control volumes, which are described through partial differential equations, with specific boundary conditions and initial conditions. Several situations are able to use this method due its relative flexibility.

Accordingly to work (Kim \& Sankar, 2011) there are resemblances between heat transfer problems and structural mechanics, as shown:

$$
\left[K_{t}\right]\{T\}=\{Q\}
$$




$$
\left[K_{s}\right]\left\{Q_{s}\right\}=\left\{F_{s}\right\}
$$

Where $\mathrm{Q}$ is the heat charge, $\mathrm{T}$ is the temperature, $\mathrm{K}_{\mathrm{t}}$ is the conductivity matrix, Fs is the force, Qs displacement and Ks are strengthening matrix.

The thermal conductivity perform an equivalent role as the longitudinal Young's modulus, temperature gradient is alike to deformation. Therefore, heat flux through the solid borders is similar to surface forces in the structure, and internally heat generated is alike forces in the body.

A similar finite method formulation can be used for heat transfer as seen in Eq. (1) and structural problems showed in Eq. (2), due similarities described previously and the finite element method division of the volume control whereas the elements maintain the properties from their origin.

According to Goldak (1984), the heat flux distribution in the arc is to be estimated through weld experimental data (melted zone, size and geometry next to the melted zone). The Figure 1 represents Goldak model:

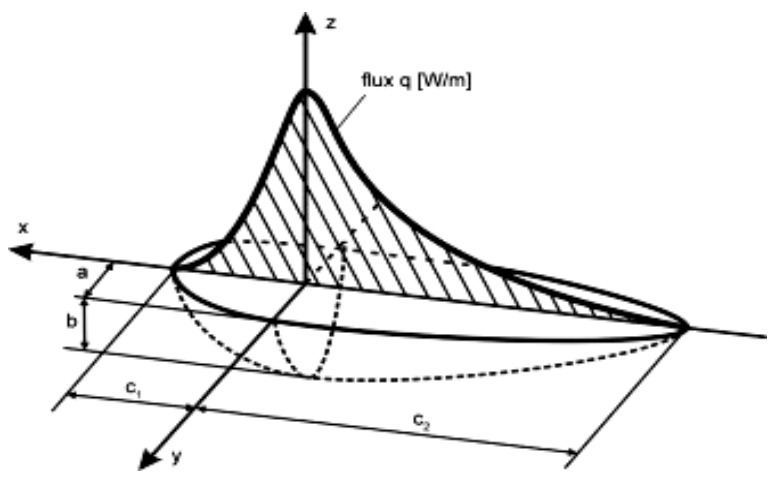

Figure 1. Dual ellipsoidal model (Goldak, 1984).

$$
\begin{aligned}
& q(x, y, z, t)=\frac{6 \sqrt{3} Q f_{f}}{a b c \pi \sqrt{\pi}} e^{\frac{-3 x^{2}}{a^{2}}} e^{\frac{-3 y^{2}}{b^{2}}} e^{\frac{-3 \xi^{2}}{c_{1}^{2}}} \\
& q(x, y, z, t)=\frac{6 \sqrt{3} Q f_{r}}{a b c \pi \sqrt{\pi}} e^{\frac{-3 x^{2}}{a^{2}}} e^{\frac{-3 y^{2}}{b^{2}}} e^{\frac{-3 \xi^{2}}{c_{1}^{2}}}
\end{aligned}
$$

Whereas ff and fr are heat fractions in the frontal and rear ellipsoids respectively with sum equal to 2 .

The heat distribution was considered to be dual ellipsoidal as in Fig. 1 and its ellipsoids described as the Eq. (3) and (4).

\section{EXPERIMENTS}

The computacional software ANSYS with educational license was used to perform the simulation in Workbench platform. The experimental data were extracted from Oliveira (2012) work, where was possible to begin the study of welding without welding laboratory, according to the work the welding initial values were set according Tab. 1.

Table 1. Values of welding variables.

\begin{tabular}{|c|c|c|c|}
\hline Sample & $\begin{array}{c}\text { Percentage }^{\mathrm{a}} \\
(\%)\end{array}$ & $\begin{array}{c}\mathrm{Vcw}^{\mathrm{a}} \\
(\mathrm{m} / \mathrm{min})\end{array}$ & $\begin{array}{c}\text { Current } \\
(\mathrm{A})\end{array}$ \\
\hline GMAW & 0 & 0 & 318.2 \\
\hline GMAW 20\% & 20 & 2 & 327.1 \\
\hline GMAW 40\% & 40 & 4 & 331.0 \\
\hline GMAW 60\% & 60 & 6 & 338.1 \\
\hline
\end{tabular}

${ }^{\mathrm{a}}$ Cold wire percentage and fed velocity

All the other welding parameters were constant to the experiments. Where $\mathrm{V}_{\text {eletrode }}=12 \mathrm{~m} / \mathrm{min}, \mathrm{U}$ $\cong 34 \mathrm{~V}, \mathrm{CC}+$, gas flow $=15 \mathrm{l} / \mathrm{min}$ and CTWD $=22 \mathrm{~mm}$

Due to an increase in current with cold wire increasing addition, this study checked if occurred an increase in the thermal cycles and if this affected the weld geometry.

The bodies-specimens were cut in the central part, due this area presents the possibility of greater stability and uniformity of the weld bead. With the sample taken from the body of the specimen was possible to screw it up to a particle size of 80 to 600 mesh and then use the chemical attack of $5 \%$ nital to reveal the weld macrostructure.

In this study, it was evaluated the thermal energy delivered to the base metal at the time, in other words the weld thermal evaluation in thermal transient. The physical properties of SAE 1020 with varying temperature were used for numerical analysis. These values were taken from the Metals Handbook Volume1.

The mesh used in the numerical modeling was initiated with $2 \mathrm{~mm}$ mesh size in the central region of the weld up to $10 \mathrm{~mm}$ to the left and right side, and in another region it was used a mesh size of $4 \mathrm{~mm}$, as can be seen in Fig. 2. This strategy was used because in the region where the mesh size is smaller there is a more refined analysis of the heat source values.

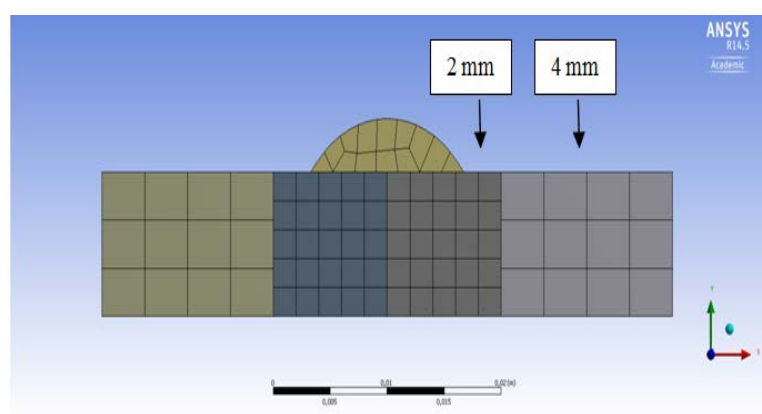

Figure 2. Mesh size used in the simulation.

\section{RESULTS AND DISCUSSION}

The Figure 3 shows the behavior of numerical analysis since the early activation of the heat source until the completion of the same, with subsequent post-heat conduction welding. Moreover, we observe 


\section{Tecnologia/Technology}

that no anomalies during the process of numerical analysis as oscillations during welding distortion or displacement of the heat source. This reminds us that in evaluating the proposed heat source model is in agreement with the parameters reported in the literature.
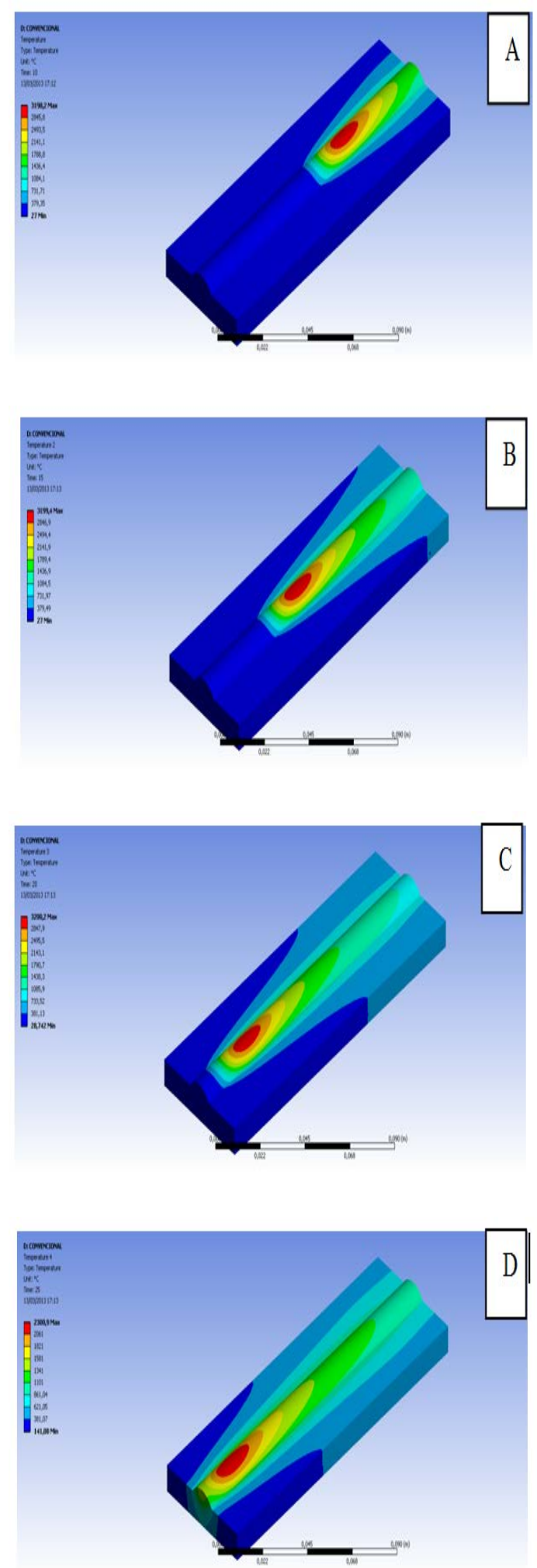

Mendonça, et al. Computer Analysis of the Gmaw and ...

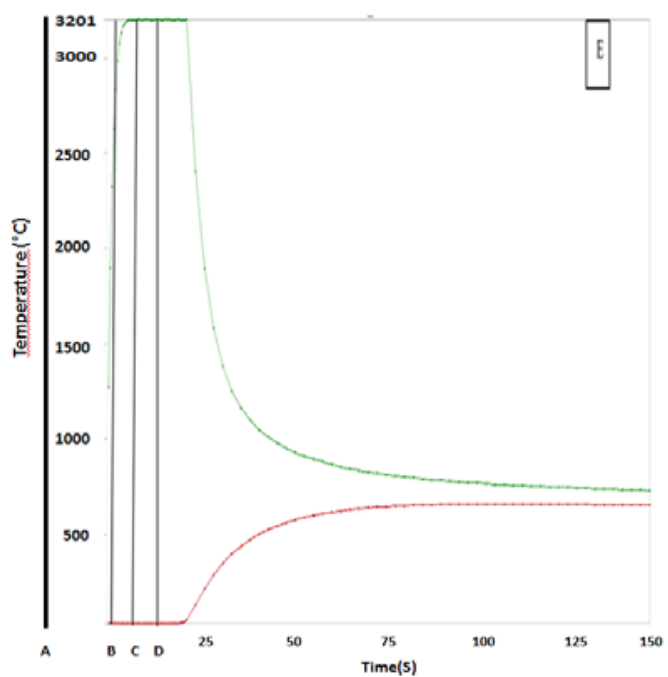

Figure 3. Representation of process simulation time of 10 seconds (A), 15 seconds (b) 20 seconds (c) 25 seconds and (D) outlining times graph $(\mathrm{E})$.

The figure 4 shows four images of the density distribution of energy from the double ellipsoid equation. With these values it was possible to obtain the numerical analysis for welded joints. Figure 5 presents the results for the conventional GMAW and the percentage additions unpowered wire 20, 40 and $60 \%$. It is observed that in the experimental analysis, as well as a decrease in the melt zone and heat affected zone by heat A to D occurred.

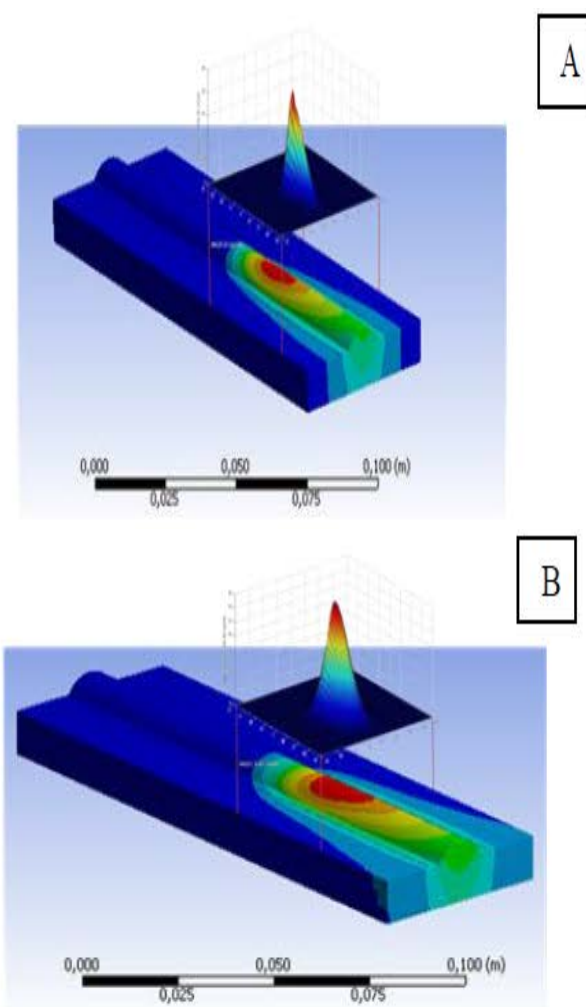




\section{Tecnologia/Technology}

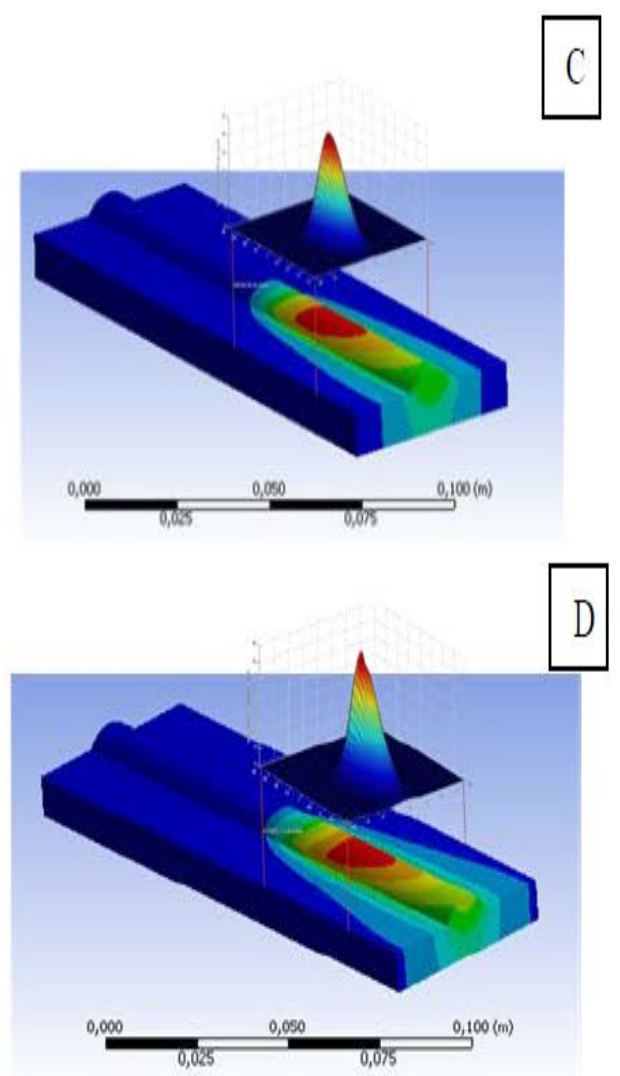

Figure 4. Density of the heat source for GMAW + GMAW processes (A) 20\% (B) + 40\% GMAW (C) and GMAW + 60\% (D).
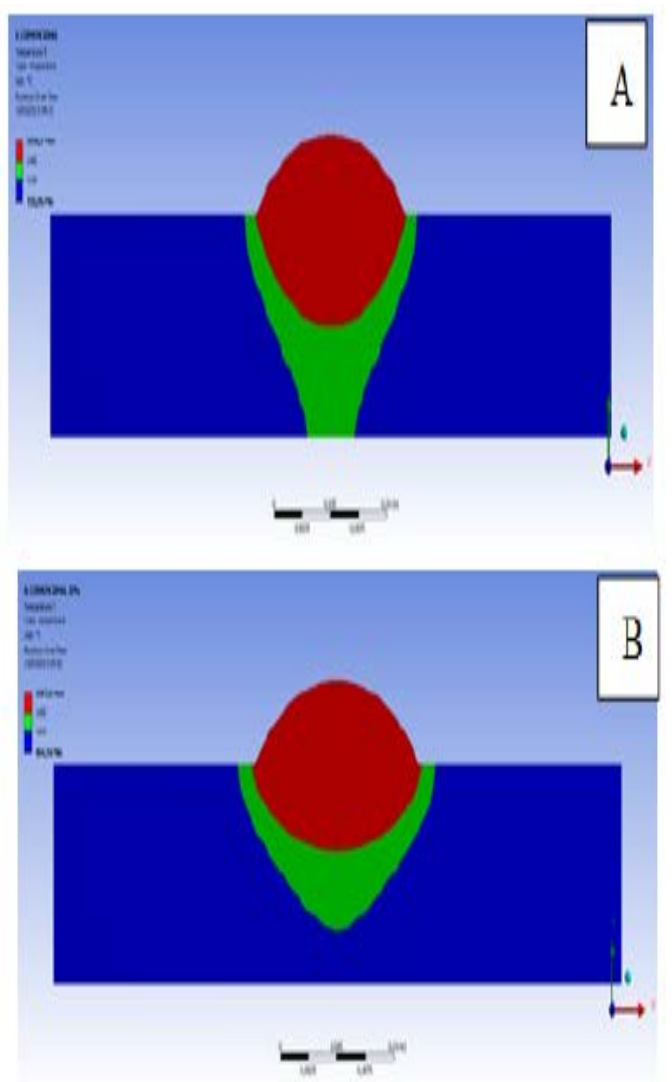

Mendonça, et al. Computer Analysis of the Gmaw and ...
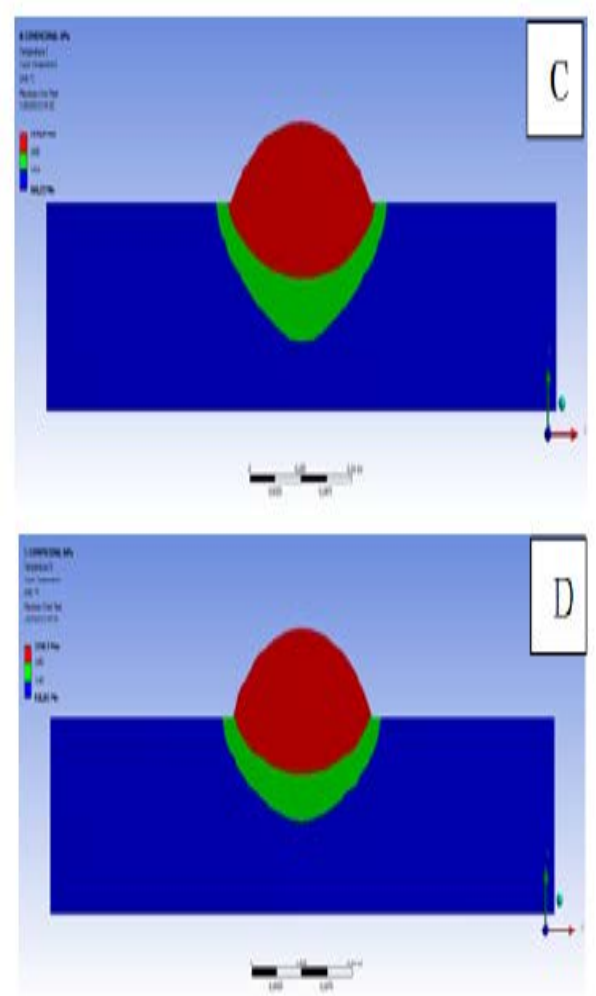

Figure 5. Macrographs of numerical analyzes (AGMAW, GMAW + B-20\%, C 40\% + GMAW, GMAW D + 60\%).

With the results of numerical analysis of temperature change in time in GMAW process, it became possible to produce thermal welding, as can be seen in Figure 6. The model presented in the fusion zone (ZF) a great depth, and a peak temperature of the solder center $1434.5^{\circ} \mathrm{C}$, according to the diagram iron-carbon 1020 steel corresponding this temperature zone for melting the material .

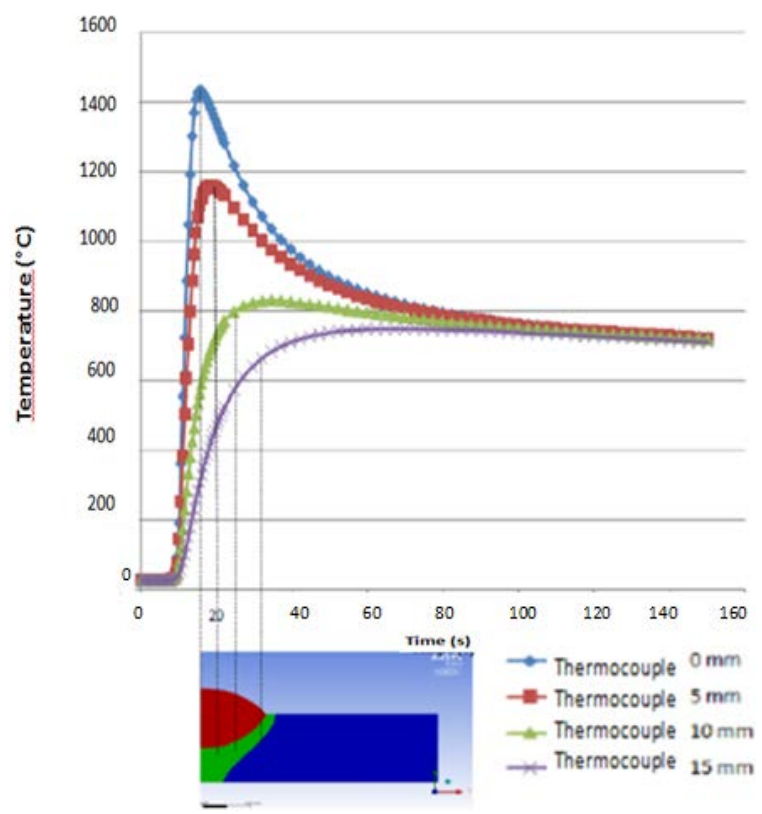




\begin{tabular}{|c|c|}
\hline $\begin{array}{c}\text { Time } \\
(\mathrm{s})\end{array}$ & $\begin{array}{c}\text { Peak Temperature } \\
\left({ }^{\circ} \mathrm{C}\right)\end{array}$ \\
\hline 15.5 & 1434.5 \\
\hline 18.5 & 1163.3 \\
\hline 34.549 & 829.6 \\
\hline 67.176 & 750.43 \\
\hline
\end{tabular}

Figure 6. Thermal cycle for the numerical model of the GMAW.

Already at distances of 10 and $15 \mathrm{~mm}$ from the center of the weld bead model generated temperature value on the order of $1100^{\circ} \mathrm{C}$, corresponding to the diagram of phases of this steel heat affected zone.

For GMAW $+20 \%$, Figure 7 shows the model in a reduced fused zone (ZF) compared with GMAW model, it shows that with the increase of deposited mass there influences the penetration weld bead in the base metal. The peak temperature in the central region of the weld was about $1285.6^{\circ} \mathrm{C}$, thus showing that there was no melting of the base metal in this region the iron-carbon diagram is observed, but most likely in the region of zone heat affected (ZTA) heat is occurring phase changes. Thus it can induce the distances between 10 and $15 \mathrm{~mm}$ from the bead center is a region perhaps grain growth, since we temperature between 840 and $640^{\circ} \mathrm{C}$.

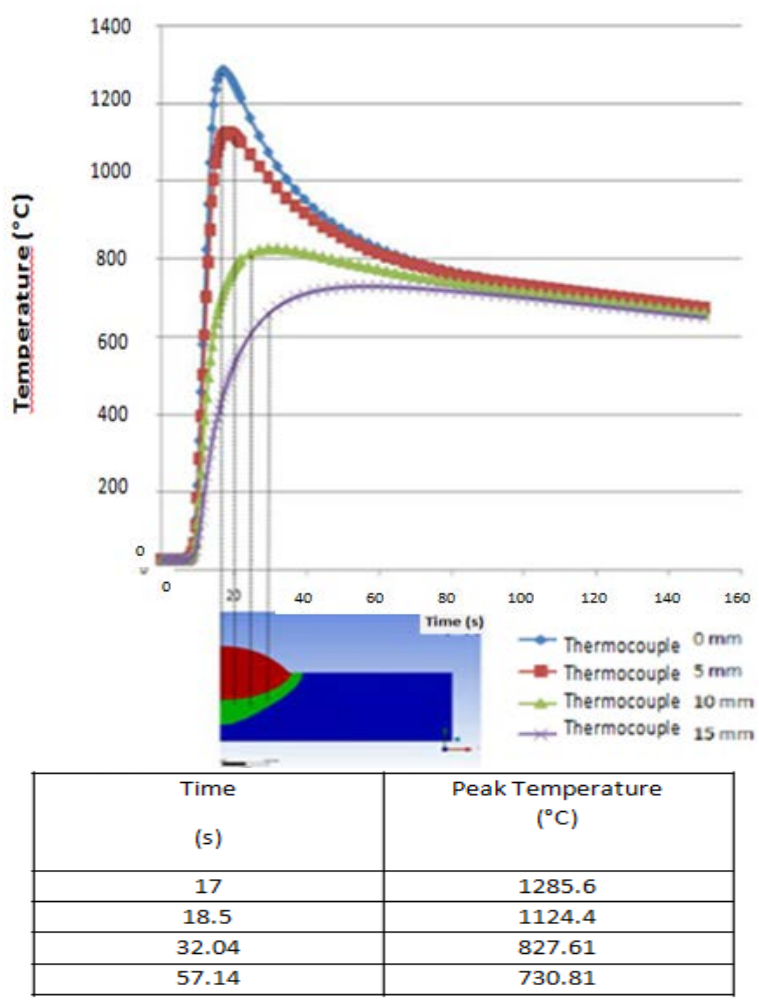

Figure 7. Thermal cycle for the numerical model of the GMAW + $20 \%$.

The more addition of cold wire occurs during welding, plus there is the retreat of the molten zone (ZF), thus becoming less heat affected zone (HAZ). With this result, it is believed that the greater the addition of cold wire is lower region of phase transformation in the base metal, with reference to the temperature values obtained in the figures thermal 8, 9 and 10 .

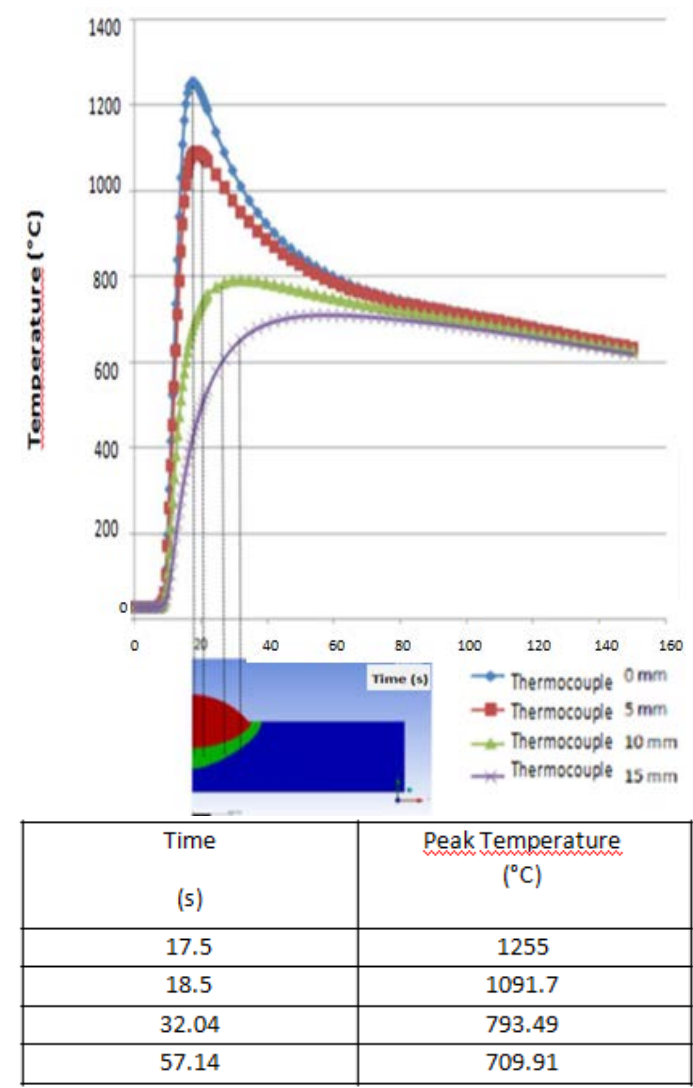

Figure 8. Thermal cycle for the numerical model of the GMAW + $40 \%$

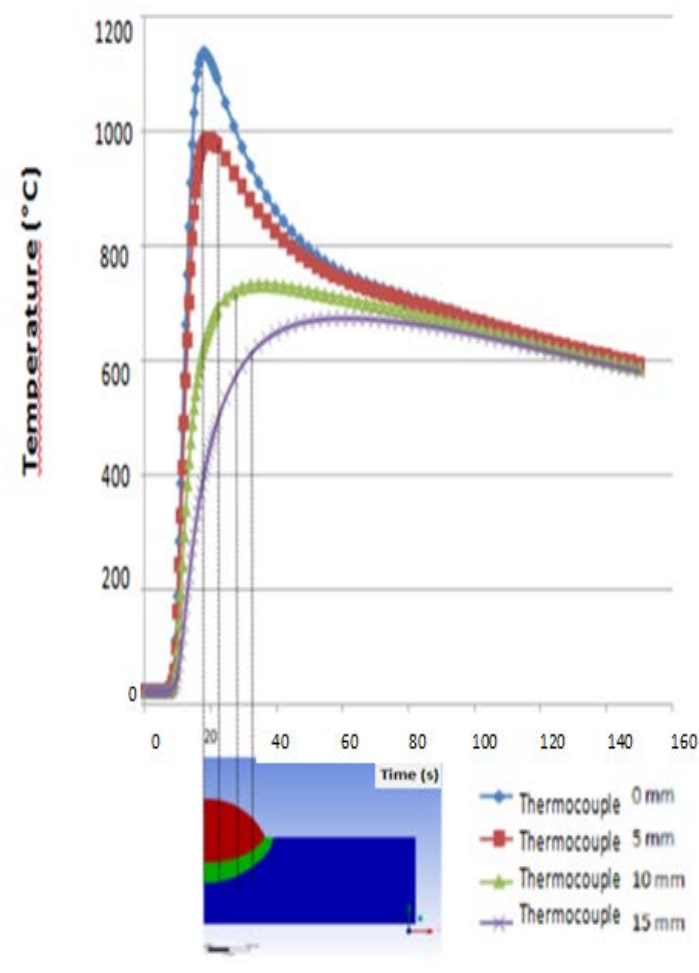




\begin{tabular}{|c|c|}
\hline $\begin{array}{c}\text { Time } \\
(\mathrm{s})\end{array}$ & $\begin{array}{c}\text { Peak Temperature } \\
\left({ }^{\circ} \mathrm{C}\right)\end{array}$ \\
\hline 18 & 1137.1 \\
\hline 19.5 & 984.09 \\
\hline 34.55 & 733.18 \\
\hline 59.65 & 673.09 \\
\hline
\end{tabular}

Figure 9. Thermal cycle for the numerical model of the Gmaw + 60\%.

The Figure 10 shows the comparison between the experimental model (left) and the numerical model (right). It is observed that the numerical model represented the experimental model above $90 \%$ for Figure 10, B and C, showing its validation. As for the Figure $10 \mathrm{D}$ model showed a percentage error of about $23 \%$, or not validating the model for this situation, there have considered accepted model with a percentage error below $10 \%$.
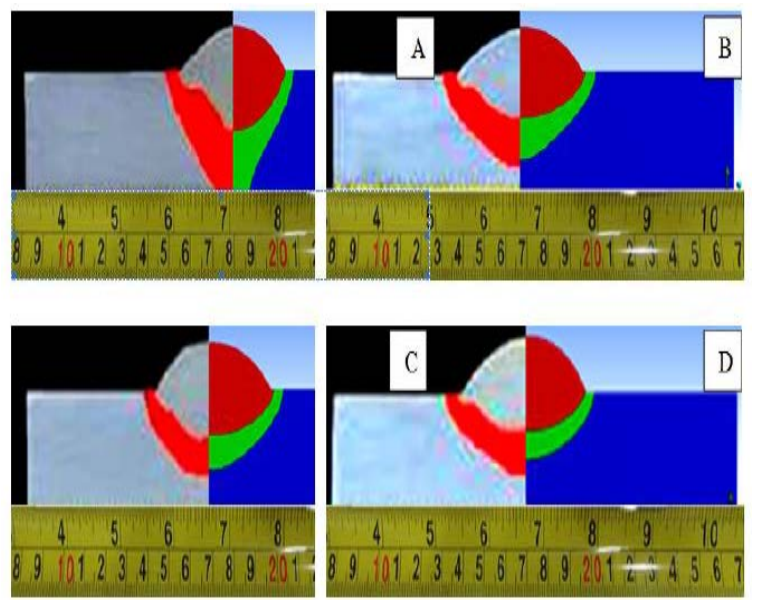

Figure 10. Comparison between the experimental macrographs results (left) and numerical (right) (AGMAW; + 20\% B-GMAW, GMAW C + 40\%, + $60 \%$ D GMAW).

\section{CONCLUSIONS}

There were not any anomalies during numerical calculations and analysis or distortions in the heat source displacement, which is in accordance to the literature used. In the particular case of GMAW-CW, the cold wire decrease $\mathrm{HAZ}$ and $\mathrm{ZF}$ area as its velocity is increased.

As observed, the temperature peak in each situation has decreased from GMAW to GMAWCW-60\%, probably due to the deposition method used in weld. And finally, percentage errors in most cases were below 10\%, except for the GMAW-CW $60 \%$ where the cold wire had its most influences.

\section{ACKNOWLEDGEMENTS}

The authors would like to thank to the LCAM of Universidade Federal do Pará, and all the persons that supported this work.

\section{REFERENCES}

Bacelar, A. R. C., and Ferraz, A. C, 2005, Study of MAG Welding Process Operational Viability with Additional Power of a Cold Wire, Work Course Conclusion, Federal University of Pará, Belém, PA.

Goldak, J. A, 1984, A New Element Model for Welding Heat Source, Metallurgical Transactions B, Vol. 15, pp. 299-305.

Kim, N, and Sankar, B. V., 2011, Introduction to Analysis and Finite Element Design, Wiley.

Oliveira, A. V. B. D, 2012, Arc Stability Study for GMAW-CW Process, Work Course Conclusion, Institute of Technology, Federal University of Pará, Belém, PA.

Sábio, A. D, 2007, Study of MAG Welding Process Operational Viability with Additional Power of a Cold Wire, Master Thesis, 146 p, Federal University of Pará, Belém, PA.

Scotti, A., and Ponomarev, V., 2008, MIG/MAG Welding: Better Understanding, Better Performance, 1. ed., Artliber. 